\title{
CINEMA
}

\section{CINEMA TENTACULAR: POÉTICAS DAS PROFUNDEZAS E A IMAGEM DO OCTÓPODE'}

\author{
TENTACULAR CINEMA: POETICS OF THE DEPTHS AND THE OCTOPUSES' IMAGE \\ CINE TENTACULAR: POÉTICA DE LO PROFUNDO Y LA IMAGEN DEL OCTÓPODO \\ Erick Felinto ${ }^{2}$
}

RESUMO: este trabalho examina uma série de diferentes obras nas quais os polvos e cefalópodes em geral podem ser pensados como criaturas particularmente "cinematográficas". Das representações populares, em filmes como Tentacles (1977), aos documentários, como Amours de la Pieuvre (1965), ou a filmes experimentais, como Mon Homme (Poulpe) (2016), a meta deste percurso será esclarecer, por um caminho "tentacular", por que razão a animalidade constitui uma das vias de acesso privilegiadas ao cinema, segundo André Bazin e Raymond Bellour.

Palavras-chave: Octópodes. Cinema. Pós-Humanismo.

ABSTRACT: this article examines a series of different works in which octopuses and cephalopods in general can be though of as particularly "cinematographic". From popular representations in films like Tentacles (1977) to documentaries such as Amours de la Pieuvre (1965) or experimental works, like Mon Homme (Poulpe) (2016), the goal of this essay is to explore the reasons why animality constitutes one of the privileged roads to access cinema, according to André Bazin and Raymond Bellour.

Keywords: Octopuses. Cinema. Posthumanism.

\footnotetext{
Uma versão preliminar deste texto foi apresentada no XXII Encontro da Sociedade Brasileira de Estudos de Cinema e Audiovisual (Goiânia), em outubro de 2018.

2 ORCID: 0000-0003-2613-5774E-mail: erickfelinto@gmail.com
} 
RESUMEN: este documento examina una serie de trabajos diferentes en los que los pulpos y los cefalópodos en general pueden considerarse criaturas particularmente "cinemáticas". Desde representaciones populares, en películas como Tentacles (1977), hasta documentales, como Amours de la Pieuvre (1965), o hasta películas experimentales, como Mon Homme (Poulpe) (2016), el objetivo de este camino será aclarar, de una manera "Por qué la animalidad es una de las rutas de acceso privilegiadas al cine, según André Bazin y Raymond Bellour.

Palabras clave: Octópodos. Cine. Posthumanism.

"É a ti que canto, polvo, coisa mole e desabitada pelo arcabouço de uma ossada pronto para a metamorphose". (Nuno Ramos, Polvo)

\section{Introdução}

"Os filmes de animais nos revelam o cinema". Com essa enigmática frase de Bazin, Raymond Bellour aponta para a conhecida paixão do crítico pela noção do cinema como revelação da realidade (2009, p. 537)3. É o aspecto "documental" do cinema (muito presente, por exemplo, nos documentários sobre a "vida selvagem") que prioritariamente lhe faria jus como arte de preservação do real que transcende tempo e espaço. Tanto Bellour como Serge Daney observam que os exemplos oferecidos por Bazin para o princípio da "montagem interdita" privilegiam situações em que animais aparecem repetidamente (BELLOUR, 2009, p. 538; DANEY, 2003, p. 33)4. Segundo este último, é nesse sentido, inclusive, que podemos perceber que "a essência do cinema se torna uma história sobre animais" (DANEY, 2003, p. 32). De fato, o interesse obsessivo de Bazin pelo animal permite mesmo justificar uma aproximação de seu pensamento com o projeto crítico

3 A frase de Bellour aparece no ensaio "Les films d'animaux nous révélent le cinema", publicado em Radio Cinéma Télévision, n. 285, jul. 1955.

4 Assim reescreve Daney o princípio baziniano da montagem interdita: "sempre que for possível enquadrar dois objetos heterogêneos na mesma tomada, a edição é proibida" (2003, p. 32). 
pós-humanista de desconstrução do antropocentrismo. Como sugere Jennifer Fay, "o cinema, e sua relação com o processo fotográfico no discurso de Bazin, pode mostrar-nos os limites da visão humana e revelar um mundo no qual humanos existem em pé de igualdade com animais e coisas" (2008, p. 42, tradução nossa)5.

Porém, mais que anedótica ou limitada ao pensamento de Bazin, essa noção parece ecoar em uma série de trabalhos recentes sobre o cinema, inclusive na própria obra de Bellour (BELLOUR, 2009; LIPPIT, 2000; BURT, 2002). De fato, em Le Corps du Cinéma, Bellour identifica nas "emoções", na "hipnose" e na "animalidade" três vias de acesso privilegiadas ao que denomina como "o corpo do cinema", esse "local virtual" da conjunção entre o vasto corpus dos filmes da história do cinema e o corpo do espectador. A figura do animal, como emblema de um organismo movido por afetos primários e radicalmente suscetível à hipnose, atravessa esse corpo de ponta a ponta. Em Akira Lippit, consequentemente, o cinema é pensado como um suplemento tecnológico do sujeito, como um inconsciente em forma de aparato. E enquanto tal, "acaba por assemelhar-se à sua contraparte na natureza, o suplemento animal” (2000, p. 25, tradução nossa) ${ }^{6}$. Em outras palavras, no cinema, animal e tecnologia se conjugam num encontro singular que produz a figura de um lócus ontológico excedendo a subjetividade e permitindo-nos, assim, repensá-la em um novo diapasão.

É desse lugar que pretendo discorrer no presente trabalho; um lugar no qual figuras marginais do pensamento filosófico - animais e tecnologias - aparecem em intrigante proximidade. Todavia, ao paradoxo de figuras que se apresentam, ao mesmo tempo, como marginais, mas obsessivamente presentes (no cinema, por exemplo), quero acrescentar um segundo, que pode ser traduzido como um encontro entre visibilidade e invisibilidade. Dentre os filmes em que o animal se torna personagem de destaque, são provavelmente aqueles que descem às profundezas do mares os mais marcados por tal paradoxo. John Durham Peters destaca nitidamente a contradição, observando que, não obstante os luminosos e coloridos ambientes marinhos que frequentemente nos são apresentados em filmes, "o oceano é um local obscuro (murky), e a luz efetivamente desaparece tão logo se alcança certa profundidade" (2015, p. 61, tradução nossa)7. Para Nicole Starosielski, por sua vez, o ambiente subaquático não somente se caracteriza

\footnotetext{
5 Do original: Cinema, and its relationship to the photographic process in Bazin's account, can show us the limits of human vision and reveal a world in which humans exist equally with animals and things.

6 Do original: comes to resemble its counterpart in nature, the animal supplement. Para uma reflexão sobre a ideia do cinema como "segunda natureza", ver Felinto (2010).

7 Do original: the ocean is a murky place, and light effectively vanishes one you reach a certain depth.
} 
como "sítio onde novas possibilidades discursivas podem ser geradas", um domínio próprio do "não humano" (2013, p. 150, tradução nossa) ${ }^{8}$, senão também como lócus no qual a história do cinema marinho se desdobra entre as figuras de misteriosos "outros" (geralmente racializados) e "nós". Se até os anos 1960, aproximadamente, o oceano era representado como território sempre pertencente a uma exótica "alteridade", desse momento em diante ele começará a ser apropriado e povoado por um tranquilizador e domesticado "nós". Em outras palavras, desenrola-se a transição de um domínio pouco visível, misterioso e obscuro para um "espaço que necessita ser socialmente contido via ciência e regulação" (STAROSIELSKI, 2013, p. 165, tradução nossa) ${ }^{9}$. Curiosamente, esse movimento de deslocamento do "outro étnico" - dos exóticos povos que vivem às margens dos oceanos - se deu por meio da eleição de novas representações da alteridade. A partir de então, a natureza dos mares tornou-se análoga à do espaço sideral: um ambiente fundamentalmente "não humano" e "extraterrestre", aberto a seus potenciais colonizadores em busca da "fronteira final". É nesse contexto, creio, que os octópodes irão ocupar papel de relevo.

O que pretendo demonstrar neste artigo é que essas criaturas marinhas funcionam - e não apenas no âmbito do cinema, senão também em várias outras dimensões da cultura - como encarnações de uma alteridade radical, alienígena, perturbadora, inclusive, das convenções tradicionais da representação. Habitando um meio que "altera as condições da produção de conhecimento" e exige a elaboração de uma nova epistemologia (JUE, 2014, p. 85, tradução nossa) ${ }^{10}$, os seres tentaculares parecem apresentar-se a nós como criaturas particularmente "cinematográficas". No cinema, elas transitam entre diferentes gêneros (do documentário ao horror e à ficção científica), mas carregando sempre as marcas de um espaço epistêmico e imagético radicalmente estrangeiro e perturbador do conhecimento humano. Personagens destacados de um "bestiário maldito", nas palavras de Roger Caillois (1973, p. 218, tradução nossa)" , elas "figuraram de forma proeminente em filmes desde há muito tempo" (ANDERSON, 1992, p. 79, tradução nossa) ${ }^{12}$. De fato, os elementos que justificariam a misteriosa frase de Bazin com que se inicia este

\footnotetext{
8 Do original: site where new discursive possibilities can be generated; nonhuman.

9 Do original: a space that needs to be socially contained via science and regulation.

10 Do original: changes the conditions of knowledge production.

1 Do original: Bestiaire maudite. Agradeço a Siegfried Zienlinski a indicação de La pieuvre, essay sur la logique de l'imaginaire como uma das possíveis fontes de inspiração do Vampyroteuthis Infernalis de Flusser. Cf. particularmente a p. 223 da obra, na qual Caillois nomeia explicitamente a criatura à qual Flusser irá dedicar, anos depois, sua fábula filosófica.

12 Do original: have long figured prominently in movies.
} 
artigo parecem estar presentes nos octópodes em forma superlativa - o que lhes garantiria, pois, um lugar especial na história do cinema.

Nesse sentido, antes de tudo, cabe perguntar o que permite vincular tão intimamente a figura do animal com a experiência cinematográfica. Para Bellour, seguindo os passos de Deleuze, o animal encarna as ideias da "intensidade", do movimento, do devir". Nos movimentos de territorialização e desterritorializaçao que atravessam a experiência animal, manifestam-se as forças primigênias da arte; irrompe uma zona de indeterminação fundamental entre natureza e cultura na qual tem lugar a atividade artística. Em Deleuze, lembremos, a arte é condensação expressiva de sensações e afetos em um material. Anterior e ultrapassando qualquer dimensão antropogênica, a arte é fundamentalmente anti-humanística. Se sua meta é alcançar a "pura sensação", algo que está para além - ou melhor, "para aquém" - da subjetividade humana, então faz sentido dizer, com Deleuze, que "a arte começa, talvez, com o animal" (DELEUZE, 1991, p. 174, tradução nossa) ${ }^{13}$. Desse modo, o "devir-animal" é parte essencial daquela "zona de indiscernibilidade" onde se constitui o processo artístico. O devir, o movimento, essas noções tão fortemente associadas a um ser que é, "antes de tudo, movimento", fazem do animal, consequentemente, uma figura por excelência do cinema - essa máquina que reinventa "segundo seu próprio modo um movimento aparente da vida" (BELLOUR, 2009, p. 431, tradução nossa) ${ }^{14}$.

Essa correlação entre animal e movimento aparece já, segundo Gilbert Durand, nos níveis mais primordiais de manifestação do imaginário. Na seção "Visages du Temps" de seu tratado sobre as estruturas antropológicas do imaginário, Durand se dedica à análise dos símbolos "theriomorfos" (de forma animal). Ali se sugere que o simbolismo animal está fundado tanto na sensibilidade aos movimentos externos quanto na ideia de multiplicidades que se agitam, da movimentação caótica (como em enxames, em coletivos animais) ${ }^{15}$. Desse modo, a espontaneidade abstrata do animal se estabelece no esquema básico da "animação", da fugacidade do tempo. O cavalo, esse animal profundamente cinematográfico ${ }^{16}$, é uma das encarnações

\footnotetext{
13 Do original: l'art commence peut-être avec l'animal. Nessas formulações de Deleuze se encontram diversos pontos de contato curiosos com a fantasia flusseriana do Vampyroteuthis Infernalis. Mais sobre isso adiante.

14 Do original: avant tout mouvement; selon son propre mode un mouvement apparent de la vie. Sobre o "devir-animal" e a problemática do movimento, ver também Lippit, 2000, p. 127.

15 Inevitável, aqui, a lembrança de Foucault e sua menção, em As Palavras e as Coisas, da enciclopédia chinesa referida por Borges, na qual se fala de animais "qui s'agitent comme des fous" (FOUCAULT, 2015, v. I, p. 1035).

16 A importância e as relações viscerais entre os cavalos e o cinema aparecem como tema da conversa entre Bruno Roberti e Nuccio Ordine na edição especial de Fata Morgana dedicada ao tema "Animalitá". Ver: VVAA, 2011, p. 12.
} 
mais populares dos símbolos theriomorfos, com seus vetores de movimento incessante. Particularmente pregnante é o imaginário do cavalo-marinho, não somente "porque o mesmo esquema de movimento é sugerido pela água corrente", senão também porque o animal é "associado à água em função do caráter aterrador e infernal do abismo aquático" (DURAND, 1969, p. 83). Associações muito semeIhantes encontram-se, também, na figura do octópode. De fato, algumas páginas depois, Durand irá arrolar o polvo como animal característico entre os símbolos nictomorfos (ligados à noite). Habitando as profundezas de águas negras onde nenhuma luz parece alcançar, associado aos poderes sombrios do feminino, o polvo é "símbolo direto da fatalidade do oceano", no qual se manifesta uma força "todo-poderosa nefasta e feminóide" (1969, p. 116, tradução nossa)17.

A conexão do cefalópode com representações de uma sexualidade simultaneamente sedutora e sombria tempo tem muito a ver com seu modo de se movimentar. Essa conexão toma forma visível em uma tradição pictórica muito singular, que parece ter origem no Japão e se firma com uma célebre gravura de Katsushika Hokusai (1760-1849), tako to ama (algo como "polvo(s) e a mergulhadora"), inicialmente publicada em 1814. Elaborado a partir de uma paródia de milenares lendas populares de motivação budista, a gravura de Hokusai se baseia em trabalhos anteriores, nos quais tanto as figuras das pescadoras (de pérolas) como as dos octópodes são fortemente sexualizadas: ali, "os múltiplos apêndices do polvo assumem um caráter fálico, executando penetração e cunilingus" (TALERICO, 2001, p. 33, tradução nossa) ${ }^{18}$. Vale assinalar que o termo tako ("polvo") era uma gíria comum no período Edo para o órgão sexual feminino - que, como um octópode, costumava ser caracterizado como capaz de sucção e de se agarrar firmemente a objetos (TALERICO, 2001, p. 34). Esse simbolismo sexualizado dos cefalópodes é destacado por Caillois, quando adverte que já os "antigos consideravam o polvo o mais libidinoso dos animais marinhos" (1973, p. 38, tradução nossa) ${ }^{19}$. Flusser também explora tal simbolismo em sua fábula sobre a "lula-vampiro do inferno", caracterizando o modo de existência natural do animal como profundamente sexual e orgiástico. Talvez a mais bela

\footnotetext{
17 Do original: Symbole direct de la fatalité de l'océan; toute-pouissance néfaste et féminoïde.

18 Do original: the multiple appendages of the octopus take on a phallic character, performing penetration and cunnilingus.

19 Do original: certains anciens ont considéré le poulpe comme le plus libidineux des animaux marins.
} 
passagem onde se evoca a ideia esteja no modo como o pensador descreve a "arte" do Vampyroteuthis na versão alemã ${ }^{20}$ do ensaio:

Arte como estratégia da violação, do ódio; arte como logro, como ficção, como mentira; arte como aparência enganosa, portanto, como "beleza" - e tudo isso na modulação do orgasmo (in der Stimmung des Orgasmus) (FLUSSER, 2002, p. 63) ${ }^{21}$.

Na animação premiada Mon homme (poulpe) (STÉPHANIE CADORET, 2016), uma mulher mantém uma relação amorosa/sexual com um polvo que habita em seu apartamento. O ambiente marinho, assim, como o polvo, produzem uma experiência que é, simultaneamente, da ordem da atração e da repulsão, do desejo e do desgosto, de beleza barroca ${ }^{22}$ e de terror, de potência vital e de contenção. O polvo move-se de forma lenta e sensual, abraçando sua parceira em modos alternadamente carinhosos e sufocantes.

No final do curta, vemos a consorte humana vestir-se para sair de casa. Em seu corpo, percebe-se a manifestação física de um processo de hibridação radical: ventosas nos braços, guelras no pescoço, cuidadosamente escondidas pelas roupas que escolhe. Em La Región Salvaje (Amat Escalante, 2016) ${ }^{23}$, uma criatura tentacular de origem alienígena é foco de atração e desejo sexual por parte das personagens femininas. Mantido em segredo em uma residência rural por um casal de cientistas, que assegura sua sobrevivência através da obtenção de parceiros compatíveis, o cefalópode extraterrestre se torna inicialmente objeto da obsessão de Verônica, jovem bela, mas perdida em uma existência insatisfatória e de perspectivas limitadas, e, em seguida, de Alejandra, mãe aprisionada em uma relação abusiva.

Em uma curiosa mescla de fantasia, ficção científica e crítica social, La Región Salvaje constitui um retrato cru de uma sociedade essencialmente misógina, hipócrita e homofóbica. Ao mesmo tempo, a criatura é uma representação visceral da sexualidade humana no que tem de mais poderoso e perigoso. Ao preparar-se para o encontro

\footnotetext{
20 Flusser escreveu ao menos três versões de Vampyroteuthis Infernalis (e com algumas importantes diferenças entre si), em português, alemão e francês.

${ }^{21}$ Do original: Kunst als Strategie der Vergewaltigung, des Hasses; Kunst als Täuschung, als Fiktion, als Lüge; Kunst als trügerischer Schein, also als 'Schönheit' - und dies alles in der Stimmung des Orgasmus.

22 Segundo a descrição da ficha técnica da animação: "Povoada de uma flora aquática barroca, a habitação se tornou o ecossistema de seu parceiro: um polvo". É nesse ambiente, "úmido e sufocante", mas também de selvagem beleza, que a protagonista passa a maior parte de seu cotidiano. Disponível em: https://www. marmitafilms.fr/project/mon-homme-poulpe/. Acesso em: 12 out. 2018.

23 Agradeço a Adalberto Müller a indicação do filme.
} 
com o misterioso ser, Alejandra recebe algumas importantes advertências de seu cuidador: "Talvez percas a vontade e a razão" (o que, de fato, acontece com Verônica); "os animais são os que estão mais em contato com suas necessidades"; "o que está ali na cabana é nossa parte primitiva, o básico, em seu estado mais puro, materializado [...]"

Por meio de seu mover malemolente, ao mesmo tempo complexo, confuso e intrigante, o octópode sempre fascinou artistas e cientistas com seus tentáculos. Seus diversos braços, que podem estar sob o controle do cérebro central ao mesmo tempo que improvisam independentemente, oferecem fonte inesgotável de interesse para os biólogos marinhos. Como observa Katherine Harmon Courage, tanto a neurociência como a robótica falharam em prover modelos úteis capazes de iluminar a complexa articulação dos tentáculos (2013, p. 77). No cinema, os cefalópodes foram frequentemente apresentados como vilões, monstros gigantes capazes de triturar seres humanos com seus poderosos tentáculos (ANDERSON, 1992). Em certos casos, mesmo quando reduzidos a dimensões diminutas - bastante mais próximas da realidade científica - os octópodes seguiram cumprindo seu papel ignóbil no cinema. Em Fantasia Sottomarina (1938), por exemplo, Rosselini narra as aventuras de um pequeno peixe tentando escapar da "agressividade assassina" de um cefalópode (BELLOUR, 2009, p. 540)24. Em uma espécie de romance da vida marinha no qual não faltam, sequer, o elemento amoroso e o final feliz, Rosselini cria uma narrativa divertida e envolvente por meio de um claro processo de antropomorfização das criaturas subaquáticas. Uma "fábula que se conclui como todas as fábulas: serenamente", conforme anuncia o narrador no final do filme.

Essa representação nefasta do cefalópode gigante aparece de forma arquetípica no romance de Jules Verne, 20 mil Léguas Submarinas. Em uma das cenas mais impactantes da novela, o submarino Nautilus é atacado por uma lula gigante e o canadense Ned Land é salvo pelo capitão Nemo de ser devorado pelo monstro.

Curiosamente, é precisamente uma versão cinematográfica de Twenty Thousand Leagues under the Sea (1916) que se apresenta como "the first submarine photoplay ever filmed". Em outras palavras, os octópodes estão ligados ao cinema subaquático desde suas origens mais remotas. $O$ filme foi produzido pela companhia de John Ernst Williamson (Submarine Film Corporation), inventor da "fotosfera" (photosphere), uma câmara de observação submarina que se conectava a um bote via um cabo de aço.

Dirigido por Stuart Paton, o filme produziu uma significativa alteração na história original. Em vez da lula, temos um polvo gigantesco que ataca não o

24 Do original: Agressivité meurtrière. 
submarino, mas sim um dos mergulhadores. Na cena, alguns personagens assistem ao embate por uma ampla janela no submarino, quase como se estivessem no cinema vendo um filme de ação.

Williamson chegou a afirmar, na época, que o público acreditou tratar-se de um encontro genuíno. Na verdade, como explica Richard Ellis, foi um dos primeiros "efeitos especiais" do cinema, dado que o polvo consistia em aparato mecânico cujos tentáculos de borracha eram inflados por jatos de ar comprimido (1994, p. 135). Em um filme anterior, Thirty Leagues under the Sea (1914), que Williamson exibiu inicialmente a um público de cientistas no museu Smithsonian, presenciamos o curioso e mortal encontro entre o próprio diretor e um tubarão - atraído para a fotosfera graças ao corpo submerso de um cavalo, e assim promovendo o encontro fílmico de dois animais profundamente cinematográficos ${ }^{25}$. Williamson apunhala o tubarão diante da câmera e depois entra na fotosfera para registrar sua agonia final.

A partir dos anos 1950, com o pânico gerado pela ameaça nuclear, o gigantismo dos polvos cinematográficos encontra também uma explicação com aparência de maior cientificidade. É o que acontece em It Came from Beneath the Sea (Robert Gordon, 1955), no qual um enorme octópode sai da fossa de Mindanao para atacar embarcações.

Com efeitos especiais desenvolvidos por Ray Harrihausen, especialista em animação com stop motion, o filme se encerra com a muito apropriada destruição do monstro por meio de um torpedo atômico. Já em Tentacles (Ovidio Assonitis, 1977), filme igualmente ruim, o povo é resultado da poluição e casualmente detesta ondas de rádio - noção que acidentalmente sugere a conexão entre polvos e tecnologias de comunicação.

Talvez, o pior dessa série seja o infame Octaman (Harry Essex, 1971), no qual a contaminação radioativa de lagos no México produz uma espécie de híbrido humano-cefalópode. Em todos esses filmes, o meio aquático é lócus de um terror de ordem inumana - ainda que muitas vezes transformado por meio da ação humana (caso das monstruosidades nucleares). O octópode é uma figura elusiva; mesmo suas proporções gigantescas são em parte obscurecidas por sua existência nas profundezas. O abismo é o domínio do sombrio, do misterioso, do invisível.

Para John Durham Peters, o oceano é, paradoxalmente, uma zona livre de "medialidade" (infenso a todas as tentativas humanas de fabricação), ao mesmo

25 Ou três, se contarmos também a presença do ser humano. Sobre a importante atividade dos tubarões no cinema poder-se-ia mencionar White Death (Zane Gray, 1936), The Sharkfighters (Jerry Hopper, 1956), Jaws (Steven Spielberg, 1975) e, mais recentemente, os indecentes Sharknado (Anthony Ferrante, 2013) e The Meg (Jon Turteltaub, 2018). 
tempo em que seria "o meio de todos os meios" (2015, p. 54). Para entender a mídia, afirma ele, é necessário começar não na terra, "mas sim no mar". Ao evocar a famosa ideia de McLuhan sobre a impossibilidade de os peixes perceberem seu elemento natural (a água), Peters destaca a necessidade da produção de contra-ambientes como instrumento de orientação (2015, p. 55). O mar, esse "outro" da terra, nos apresenta uma perspectiva por meio da qual podemos sair de nosso ambiente para ir ao encontro de estranhas criaturas alienígenas - como os cefalópodes. Talvez o cinema subaquático, e particularmente os filmes sobre seres marinhos, possa nos oferecer interessantes contra-ambientes.

De fato, pode ser esse um dos principais efeitos produzidos por filmes como os de Jean Painlevé, nos quais o elemento científico é "perturbado" por tonalidades surrealistas e componentes fabulatórios. É o que Ralph Rugoff define como "uma aventura na estética da estranheza (uncanniness)" (2000, p. 49) ${ }^{26}$. Rugoff nota, ainda, a importância do movimento (animal) nos filmes do documentarista. 0 meio aquático confere a tais movimentos uma graça comparável à do balé. Mais que isso, interessa observar que, em geral, "o movimento assume uma qualidade estranha (uncanny) quando provoca confusão no que diz respeito ao caráter de sua fonte" (RUGOFF, 2000, p. 52) ${ }^{27}$. Em outras palavras, ele nos coloca diante da clássica questão freudiana sobre a incerteza quanto a alguma coisa ser viva ou inanimada ${ }^{28}$. Movimentando-se diante das câmeras em contraditórias mesclas de caos e ordenação, rapidez e morosidade, os animais de Painlevé figuram as possibilidades ilusionistas do cinema e a irrealidade da ciência. Em seus filmes, a ciência se torna uma espécie de ficção do real, e o animal se converte em ser mágico que ajuda a revelar a magia do cinema. De fato, o documentarista parecia crer que o filme científico representava o domínio de exploração máxima das possibilidades do aparato cinematográfico. Como escreveu Painlevé:

Originando-se como cronofotografia a partir do trabalho do fisiologista Etienne-Jules Maray (que cedo reconheceu todas suas aplicações), o cinema é usado com efeito máximo nos mundos invisíveis da microscopia (seja microscopia ordinária, de fase-contraste ou interferência), assim como no ambiente subaquático. O movimento - que é, naturalmente, a característica distintiva do cinema - é estudado em plantas

\footnotetext{
26 Do original: an adventure in the aesthetics of uncanniness.

27 Do original: takes on an uncanny quality when it provokes confusion regarding the character of its source.

28 Rugoff não menciona Freud, mas o contexto deixa evidente a conexão com a noção freudiana do "Unheimliche", a inquietante estranheza. Ver FREUD, 1976.
} 
e animais, mas, como na astronomia, requer-se a fotografia de lapso de tempo (2000, p. 165, tradução nossa) ${ }^{29}$.

Em seu singular interesse pelo mistério do animal, Painlevé confere lugar de destaque às criaturas marinhas e, talvez, mais particularmente, aos octópodes, personagem fundamental de trabalhos como La Pieuvre (1928) e Amours de la Pieuvre (1965). Nesses filmes, o polvo é simultaneamente fonte de assombro e componente de intrigantes composições estéticas, como nas cenas em que se arrasta sobre um boneco, nos galhos de uma árvore e em um crâneo humano submerso.

Se La Pieuvre é basicamente uma sequência de imagens cuja único elo comum parece ser o desejo de capturar o mistério e a estranha beleza do octópode, Les Amours de La Pieuvre poderia ser lido como uma atualização (em cores) do primeiro filme. Até mesmo o tema da respiração (que denuncia a presença oculta do polvo) aparece aqui repetido. Todavia, no segundo documentário, o foco recai sobre os processos de acasalamento do cefalópode. Mesmo assim, a pele e os movimentos dos seres tentaculares são novamente o elemento que atrai continuamente a câmera, ao passo que a narração se apresenta como distanciada, quase científica, ainda que ocasionalmente se permita certas licenças poéticas (como o "animal horrifique" do início do filne).

Painlevé recorda que seu fascínio com os polvos nasceu de encontros ocorridos na infância e na juventude. Chamava-Ihe atenção, particularmente, a capacidade de expressão emocional dos octópodes por meio da coloração da pele: "sempre que me via, [o polvo] ficava preto; as três camadas de sua pele - azul, vermelho e verde - inchavam com prazer". Mais que isso, porém, impressionou-o a percepção de que o molusco tinha extraordinária memória dos eventos e parecia "tão inteligente como um humano" (2000, p. 174-175, tradução nossa) ${ }^{30}$.

Não surpreende que a pele de cores cambiantes e texturas sedutoras seja elemento primordial de interesse de um cineasta. A ideia de que os corpos dos moluscos podem ser comparados a uma tela já foi desenvolvida tanto em textos científico-acadêmicos (GODFREY-SMITH, 2016, p. 108) quanto em ensaios nos quais a ciência é paradoxalmente acoplada à literatura e à imaginação fabulatória. Em sua ficção filosófica sobre o Vampyroteuthis Infernalis, Vilém Flusser chega

\footnotetext{
29 Do original: Originating as chronophotography from the work of physiologist Etienne-Jules Marey (who soon recognized all its applications), film is used to optimal effect in the unseen worlds of microscopy (whether it be ordinary microscopy, phase-contrast, or interference) as well as underwater. Movement - which is of course film's distinguishing characteristic - is studied in plants as well as in animals, but as in astronomy, time-lapse photography is generally required.

3o Do original: "As intelligent as a human".
} 
mesmo a descrever o mundo urdido pelo protagonista tentacular da história com elementos que poderiam ser considerados como propriamente cinematográficos:

a noite eterna do Vampyroteuthis se enche de feixes coloridos e sons, que emergem dos seres vivos. Um eterno espetáculo de cor e som (ein ewiges Farb- und Tonspiel), um "son et lumière" de extraordinária riqueza [...] Um ruidoso jardim, que o Vampyroteuthis, por sua própria vontade, ilumina, de modo a saborear seus frutos em beleza (FLUSSER, 2002, p. 36, tradução nossa) ${ }^{31}$.

Em uma referência ainda mais direta, Flusser compara a pele do Vampyroteuthis a uma superfície imagética na versão em português da sua fábula filosófica: "o papel fotográfico é para o fotógrafo o que a pele é para o Vampyroteuthis: suporte de mensagens coloridas" (2011, p. 122, grifo nosso).

Ao tornar a lula o personagem central de seu ensaio, Flusser propõe uma superação do antropocentrismo, de modo que possamos observar nossas condições existenciais a partir do ponto de vista (Standpunkt) desse estranho ser (2002, p. 15). Emergindo como um espelho invertido do humano, representado como um alienígena que nos confronta com a alteridade mais radical, o personagem de Flusser no oferece a possibilidade de um olhar insuspeito sobre nós mesmos e sobre os outros seres com quem dividimos o mundo.

Acompanhar a lula-vampiro em sua descida às profundezas é uma experiência, acima de tudo, visual, dada sua capacidade de "projetar cores e luzes" nas trevas de seu habitat (FLUSSER, 2002, p. 22, tradução nossa) ${ }^{32}$. Suas formas de comunicação corporais, segundo Flusser, fazem lembrar nossas mídias contemporâneas (2002, p. 23). Se a analogia é válida, deparamo-nos com uma suprema ironia quando Sly Montgomery, em seu livro The Soul of an Octopus, narra a chegada a um aquarium, via correio, de um octópode embalado no que originalmente era uma caixa feita para transportar um televisor flat-screen de 27 polegadas (2015, p. 95).

Entretanto, não são apenas os recursos de camuflagem e comunicação do "corpo-tela" dos octópodes que os tornaram personagens de particular relevância na história do cinema. Os mistérios que os envolvem cruzam-se com outro tema que sempre foi caro ao universo cinematográfico: a representação do alienígena.

31 Do original: Die ewige Nacht des Vampyroteuthis wird von Farbstrahlungen und Tönen erfüllt, die von Lebewesen ausgehen. Ein ewiges Farb- und Tonspiel, ein 'son et lumière' von außerordentlichen Reichtum.

32 Do original: farben und Lichter projizieren. 
Destacando a importância da imaginação do extraterrestre na literatura e no cinema, Ziauddin Sardar observa que as presenças alienígenas

são as antíteses sombrias que iluminam os fachos de luz na estrutura das histórias, colocando em relevo o que significa ser humano. Extraterrestres ilustram à perfeição aquilo que não é humano, de modo a exemplificar o que é humano. Diferença e alteridade são a essência dos alienígenas, pois apenas assim eles podem reforçar o sentido de do self e da preservação do self que completa a cadeia da ficção científica como gênero normativo (2002, p. 6, tradução nossa) ${ }^{33}$.

E, de fato, poucas criaturas na Terra corporificam a ideia de uma alteridade radical e extraterrestre como os polvos. Essa conexão parece ter conquistado particular popularidade em anos recentes, tanto na grande imprensa - que não se cansa de explorar a estranheza alienígena dessas criaturas - como em obras científicas. Para Peter Godfrey-Smith, por exemplo, o encontro com os octópodes é "o mais perto que conseguiremos chegar de nos deparamos com um alienígena inteligente" (2016, p. 9, tradução nossa) ${ }^{34}$. Um artigo publicado recentemente em Progress in Biophysics and Molecular Biology chega mesmo a sugerir a possibilidade de que material genético dos cefalópodes tenha chegado à Terra via meteoros na forma de "ovos criopreservados" (um fenômeno que é definido como "panspermia") (STEELE e outros, 2018, p. 12)35. Partindo da incrível complexidade do DNA cefalópode e de algumas estranhas particularidades suas, ao mesmo tempo que destacando sua inteligência e seu sofisticado sistema nervoso, o grupo de cientistas responsáveis pelo trabalho não hesita, pois, em aventar a hipótese de uma origem extraterrena dessas criaturas. Na verdade, não apenas os octópodes, mas o oceano como um todo tem sido caracterizado recentemente como um espaço alienígena (HELMHEICH, 2009).

Desse modo, o cinema foi quase "presciente" ao sugerir tal conexão desde pelo menos meados dos anos $1950^{36}$. Nos últimos anos, porém, o tema apareceu de

33 Do original: they are the dark antithesis that illuminates the patches of light within the structure of stories, throwing into relief what it is to be human. Aliens demonstrate what is not human the better to exemplify that which is human. Difference and otherness are the essence of aliens, for only then can they stiffen the sense of self and self-defence that completes the chain of science fiction as normative genre.

34 Do original: the closest we will come to meeting an inteligente alien.

35 Do original: Cryopreserved eggs.

36 Ele é precedido, porém, pelos mitologemas de Lovecraft, nos quais figuras como Cthulhu, estranho e monstruoso ser tentacular, chegaram à Terra em remotíssimo passado vindos de distantes sistemas planetários. Imagino o quão divertido seria produzir uma leitura lovecraftiana a partir da filosofia política do Carl Schmitt 
forma obsessiva. Em filmes como o excelente Monsters (Gareth Edwards, 2010), os alienígenas, que muito apropriadamente habitam a zona fronteiriça entre os Estados Unidos e o México, tem formas cefalopódicas. Após uma sonda da Nasa cair no território mexicano, emerge uma "zona infectada" habitada por gigantescos seres tentaculares. Um fotojornalista americano atravessa a área em uma tentativa de resgatar a filha de seu patrão e leva-la de volta aos EUA. A metáfora central do filme, a relação entre aliens e illegal aliens (por exemplo, mexicanos que imigram ilegalmente aos Estados Unidos), já havia sido inteligentemente explorada por Man in Black (Barry Sonnenfeld, 1997) ${ }^{37}$. Na bela e espectral cena final do filme, os protagonistas observam, extasiados, o ritual de acasalamento entre dois extraterrestres. Os corpos e tentáculos das criaturas, que mais parecem correntes de lâmpadas de led, emprestam aos extraterrestres um caráter particularmente cinematográfico (como sucede com a bioluminescência do Vampyroteuthis, segundo Flusser).

Como anteriormente assinalado, a conexão entre os polvos e a imaginação do extraterrestre não é uma novidade no cinema. Em Invaders from Mars (1954), Voyage to the Prehistoric Planet (1965), Space Amoeba (1970) e, claro, Alien (Ridley Scott, 1979) encontramos exemplos de criaturas cefalopódicas. Todavia, essa associação parece realmente explodir a partir dos anos 2000, com filmes como Skyline (Colin Strause, 2010), Grabbers (Jon Wright, 2012), Europa Report (Sebastián Cordero 2013), La Región Salvaje (Amat Escalante, 2016) e Life (Daniel Espinosa, 2017), por exemplo. Arrival (2016), de Denis Villeneuve é certamente o trabalho mais interessante dessa série. Uma raça de alienígenas inteligentes, denominados de "heptapods" (devido aos seus sete tentáculos), chega à Terra, e a linguista Louise Banks (Amy Adams) é convocada para decifrar sua comple$x a$ linguagem ${ }^{38}$. A mensagem dos extraterrestres é fundamental para o futuro da humanidade, já que tais criaturas experimentam o tempo na forma de uma simultaneidade radical, e, portanto, conseguem enxergar as ameaças que podem atingir-nos em um futuro próximo.

\footnotetext{
de Land und Meer. Deixando claro que o homem não é peixe ou pássaro (2011, p. 8), mas sim um ser da terra (Landwesen), Schmitt discorre, contudo, sobre os Fishmenschen ("homens-peixe") (2011, p. 10), esses seres estranhos das culturas aquáticas para os quais olha com decidida desconfiança. A nós, homens da terra, suas representações de tempo e espaço parecem "alienígenas e incompreensíveis" (fremd und unverständlich) (SCHMITT, 2011, p. 10). Lendo essas passagens, é quase impossível não lembrar de contos como Dagon ou The Shadow over Innsmouth.

37 Que, casualmente, também apresenta a figura de um alienígena tentacular.

38 Sobre Arrival, ver, ainda: FELINTO, 2018.
} 


\section{Considerações finais}

Essa recente ampliação do interesse do cinema de ficção científica pelos octópodes parece seguir uma tendência que se manifesta, também, curiosamente, no universo do pensamento teórico e da reflexão acadêmica. Em um interessante artigo publicado na Times Higher Education, Roger Luckhurst sugere que os monstros tentaculares vêm alimentado a teoria crítica de modos insuspeitos nos últimos anos. Esse movimento intelectual, se é que assim o podemos definir, vem sendo nomeado como "The New Weird"39, e "apresenta polvos, lulas-vampiro e cefalópodes levemente estranhos com surpreendente frequência"40.

A fonte primária de inspiração para essas estranhas elucubrações se encontra no escritor norte-americano H.P. Lovecraft e sua célebre criatura tentacular, o poderoso Cthulhu. Para Luckhurst, esse fascínio com os octópodes expressa essencialmente a ideia de "alteridade", daquilo que é difícil (senão impossível) de traduzir em nossa linguagem corrente, mas que poderia ser conceitualizado como uma "pedagogia tentacular"41. Exemplo interessante desse novo tipo de empresa intelectual é o livro de Eric Wilson, The Republic of Cthulhu (2016), no qual a obra de Lovecraft é usada como instrumento para pensar uma estética característica do campo "parapolítico" - ou seja, toda sorte de instituição clandestina ou agência de inteligência que se mantém à margem das esferas oficiais do estado. Entretanto, essa onda de novas abordagens críticas inspiradas pelo gótico e pelos polvos parece estar apenas se formando nas praias do pensamento teórico. Apenas a título de exemplo, poder-se-ia mencionar ainda Tentacles Longer than Night (2015), de Eugene Thacker, e Slime Dynamics (2012), de Ben Woodard42.

Todos esses estranhos movimentos no cenário cultural contemporâneo apontam para um interesse crescente pelas categorias da "alteridade", do "alienígena", do "distante", ou, para usar a certeira expressão de Peter Szendi, do "todo outro" (tout autre) (2011). No cinema, a noção de "outridade" (otherness) sempre foi intensa-

39 O termo é ambíguo, já que designa um estilo literário (por exemplo, as novelas e contos de China Mieville ou Thomas Ligotti) ao mesmo tempo que uma corrente de pensamento crítico nas intercessões entre filosofia e estudos culturais.

40 Do original: Features octopuses, vampire squids and slightly stranger cephalopods with startling frequency. Disponível em: https://www.timeshighereducation.com/comment/opinion/tentacles-the-new-fangs-and-teaching-tool/2013987.article. Acesso em: 16 set. 2018.

41 Do original: tentacular pedagogy.

42 É bem verdade que o "New Weird" encontra precursores importantes nos trabalhos do CCRU (Cybernetic Culture Research Unit) dos anos 1980, especialmente por via de Nick Land e Reza Negarestani. A respeito do CCRU, abrigado no departamento de filosofia da Universidade de Warwick, ver Simon Reynolds, disponível em: http://energyflashbysimonreynolds.blogspot.com/2009/11/renegade-academia-cybernetic-culture.html. Acesso em: 13 maio 2017. 
mente tematizada, seja por meio do feminino (HARINGTON, 2018), do outro racial (RICHARDSON, 2010) ou do alienígena e do sobrenatural como figuras simbólicas da relação filosófica entre o "mesmo e outro" (SARDAR; CUBITT, 2002). Os cefalópodes, como criaturas carregadas com o simbolismo da alteridade alienígena, ao mesmo tempo que associadas ao imaginário das tecnologias imagéticas (FLUSSER, 2002; MELLAMPHY; MELLAMPHY, 2014; GODFREY-SMITH, 2016), deveriam, pois, ocupar uma posição especial em uma possível história do cinema como figuração da alteridade, como dialética entre o visível e o invisível, entre o próximo e o distante. Aqui, a ideia de uma conversação inter-espécies ganha importantes contornos. Ultrapassar o antropocentrismo significa entrar em relação com formas de alteridade que estão ao mesmo tempo próximas e distantes de nós. Se o cinema é uma interrogação sobre o visível e o cinema fantástico, particularmente, uma exploração do invisível, como sugere Gonzalo de Lucas (2001), os filmes podem nos ensinar a enxergar outros reinos da experiência, outros domínios da existência para além das fronteiras humanas do olhar e do pensamento.

É nesse sentido, precisamente, que Flusser nos incita a nos engajarmos em uma conversação com os alienígenas existentes aqui mesmo, sobre a superfície de nosso planeta. Sim, esqueçamos por um momento os alienígenas de mundos distantes e busquemos as estranhas formas de vida habitando, por exemplo, "os mares profundos", nas regiões que "ainda encontram-se em grande parte encobertas para nós" (FLUSSER citado por FELINTO; SANTAELLA, 2012, p. 179). Mesmo a imaginação de seres nativos de Vênus, Marte ou Júpiter, algo que seria para nós "desproporcionalmente estrangeiro, como um polvo gigante" (FLUSSER citado por FELINTO; SANTAELLA, 2012, p. 181), não é nada comparado aos mistérios animais que se encontram aqui mesmo, na Terra. "Uma conversação com uma única espécie diferente (frenden Art) alteraria nossa própria espécie de modo fundamental", escreve Flusser (FLUSSER citado por FELINTO; SANTAELLA, 2012, p. 181). Não seria o cinema um campo cultural interessante para empreender tal conversação? Para Bazin, pelo menos, com certeza. Afinal, assim como os filmes de animais nos revelam o cinema, "o cinema nos ensina a melhor conhecer os animais" (BAZIN citado por BELLOUR, 2009, p. 537, tradução nossa) ${ }^{43}$.

43 Do original: Le cinéma nous apprend à mieux connaître les animaux. 


\section{Referências}

ANDERSON, Roland. 20.000 Tentacles under the Sea: Cephalopods in Cinema. Of Sea and Shore, [S. l.], v. 15, n. 2, p. 79-84, Summer 1992.

BELLOUR, Raymond. Le corps du cinema: hypnoses, émotions, animalités. Paris: P.O.L, 2009. https://doi.org/10.3917/rai.038.0125

CAILLOIS, Roger. La pieuvre: essai sur la logique de l'imaginaire. Paris: La Table Ronde, 1973.

COURAGE, Katherine Harmon. Octopus! The most mysterious creature in the sea. New York: Penguin, 2013.

DANEY, Serge. The screen of fantasy (Bazin and Animals). In: MARGULIES, Ivone. Rites of realism: Essays on corporeal cinema. Durham: Duke University Press, 2003. https:// doi.org/10.1215/9780822384618-004

DELEUZE, Gilles; GUATTARI, Felix. Qu'est-ce que la philosophie? Paris: Les Éditions de Minuit, 1991. https://doi.org/10.7202/027380ar

DE LUCAS, Gonzalo. Vida secreta de las sombras: Imágenes del fantástico en el cine francés. Barcelona: Paidós, 2001.

DURAND, Gilbert. Les structures anthropologiques de l'imaginaire. Paris: Bordas, 1969.

ELLIS, Richard. Monsters of the sea: The history, natural history, and mythology of the oceans' most fantastic creatures. New York: Knopf, 1992.

FAY, Jennifer. Seeing/Loving Animals: André Bazin's Posthumanism. Journal of Visual Culture, London, v. 7, n. 1, p. 41-64, 2008. https://doi.org/10.1177/1470412907088175

FELINTO, Erick. Vampyroteuthis: a segunda natureza do cinema - a matéria do filme e o corpo do espectador. Flusser Studies 10. Lugano: Universitá della Svizzera Italiana, 2010.

FELINTO, Erick. Oceano digital: Imaginário marinho, tecnologia e identidade em Vilém Flusser. Galáxia, São Paulo, v. 39, p. 110-123, set./dez. 2018. https://doi.org/10.1590/1982255434444

FLUSSER, Vilém. Vampyroteuthis infernalis: Eine abhandlung samt befund des Institut Scientifique de Recherche Paranaturaliste. Göttingen: European Photography, 2002.

FLUSSER, Vilém. Seres de um outro mundo. In: FELINTO, Erick; SANTAELLA, Lucia. O Explorador de abismos: Vilém Flusser e o pós-humanismo. São Paulo: Paulus, 2012. https://doi.org/10.15448/1980-3729.2012.3.12905

FLUSSER, Vilém. Vampyroteuthis Infernalis. São Paulo: Annablume, 2011. 
FOUCAULT, Michael. Oeuvres Paris: Gallimard, 2015. 2 v.

FREUD, Sigmund. Obas psicológicas completas. Rio de Janeiro: Imago, 1976. (Edição Standard das Obras Psicológicas Completas de Sigmund Freud, v. XVII). https://doi. org/10.1590/s1415-47142011000300012

GODFREY-SMITH, Peter. Other minds: the octopus, the sea, and the deep origins of consciousness. New York: Farrar, Strauss and Giroux, 2016. https://doi.org/10.1007/ $\underline{\text { s10539-018-9650-2 }}$

HARRINGTON, Erin. Women, monstrosity and horror film: Gynaehorror. London: Routledge, 2018. https://doi.org/10.4324/9781315546568

HELMREICH, Stefan. Alien ocean: anthropological voyages in microbial seas.

Berkeley: University of California Press, 2009. https://doi.org/10.1111/j. $1467-9655.2010 .0166135 . x$

JUE, Melody. Vampire Squid Media. Grey Room n. 57. Cambridge: The MIT Press, 2014. https://doi.org/10.1162/grey_a_00155

LIPPIT, Akira Mizuta. Electric animal: Toward a rhetoric of wildlife. Minneapolis: University of Minnesota Press, 2000. https://doi.org/10.1162/leon.2009.42.3.269

MELLAMPHY, Dan; MELLAMPHY, Nandita Biswas. From the digital to the tentacular, or from iPods to cephalopods: Apps, traps, and entrées-without-exit. In: MILLER, Paul D.; MATVIYENKO, Svitlana. The imaginary app. Massachussets: The MIT Press, 2014. https://doi.org/10.7551/mitpress/9820.003.0025

MONTGOMERY, Sly. The soul of an octopus: a surprising exploration into the wonder of consciousness. New York: Atria Books, 2015.

PAINLEVÉ, Jean. Scientific film. In: BELLOWS, Andy Masaki; McDOUGALL, Marina; BERG, Brigitte. Science is fiction: the films of Jean Painlevé. Cambridge: The MIT Press, 2000. https://doi.org/10.1086/385168

PETERS, John Durham. The marvelous clouds: toward a philosophy of elemental media. Chicago: The University of Chicago Press, 2015.

RICHARDSON, Michael. Otherness in Hollywood Cinema. New York: Continuum, 2010. ROBERTI, Bruno; ORDINE, Bruno. Ambivalenza dell'ainimalitá. Conversazione con Nuccio Ordine. Fata Morgana Cosenza: Pellegrini, 2011. v. 14.

RUGOFF, Raplh. Fluid Mechanics. In: BELLOWS, Andy Masaki; McDOUGALL, Marina; BERG, Brigitte. Science is fiction: the films of Jean Painlevé. Cambridge: The MIT Press, 2000. https://doi.org/10.1086/385168 
SARDAR, Ziauddin. Introduction. In: SARDAR, Ziauddin; CUBITT, Sean. Aliens R us: the other in science fiction cinema. London: Pluto Press, 2002. https://doi.org/10.3366/ film.2003.0020

SCHMITT, Carl. Land und wesen: Eine weltgeschichtliche betrachtung. Stuttgart: Klett-Cota, 2011. 1942.

STAROSIELSKI, Nicole. Beyond fluidity: a cultural history of cinema underwater. In: CUBITT, Sean; RUST, Stephen; MONANI, Salma (org.). Ecocinema: Theory and practice. New York: Routledge, 2013.

STEELE, Edward J. e outros. Cause of cambriam explosion - Terrestrial or cosmic?. Progress in biophysics and molecular biology, Oxford, v. 136, p. 3-23, Aug. 2018.

SZENDY, Peter. Kant chez les extraterrestres: philosofictions cosmopolitiques. Paris: Minuit, 2011.

TALERICO, Danielle. Interpreting sexual imagery in Japanese prints: a fresh approach to Hokusai's 'diver and two octopi'. Impressions, New York, n. 23, p.24-41, 2001.

THACKER, Eugene. Tentacles longer than night. Winchester: Zero Books, 2015. (Horror of philosophy v. 3).

VVAA. Fata Morgana n. 14: Animalitá. Cosenza: Università della Calabria, 2011.

WILSON, Eric. The republic of Cthulhu: Lovecraft, the Weird Tale and conspiracy theory. Goleta: Punctum Books, 2016.

WOODARD, Ben. Slime dynamics. Winchester: Zero Books, 2012. 


\section{Dados do autor:}

\section{Erick Felinto - erickfelinto@gmail.com}

Pesquisador do CNPq e professor do Programa de Pós-Graduação em Comunicação da Universidade do Estado do Rio de Janeiro - UERJ. Pós-Doutorado em Teorias da Mídia Alemã, pela Universität der Kunste Berlin, e Doutorado em Letras pela Universidade do Estado do Rio de Janeiro - UERJ.

\section{Endereço do autor:}

Universidade do Estado do Rio de Janeiro, Faculdade de Comunicação Social - Rua São Francisco Xavier 524, sala 10129F - Maracanã, 20.550-013 - Rio de Janeiro (RJ), Brasil 